NASA Contractor Report 175094

\title{
Effects of State Recovery on Creep Buckling Under Variable Loading
}

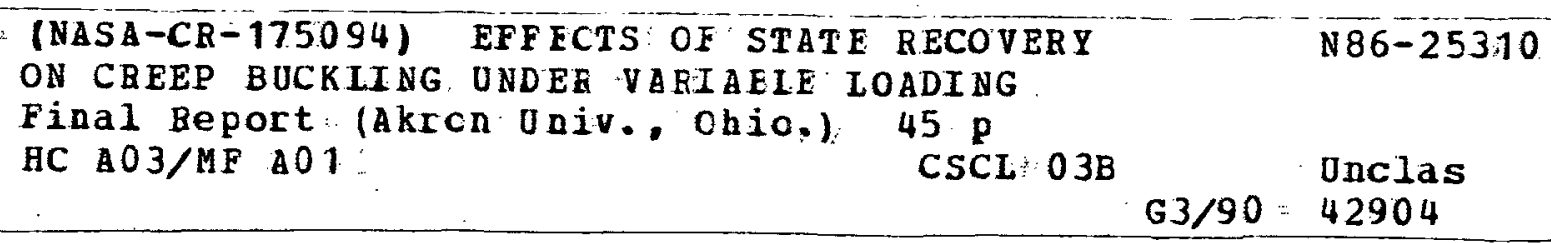

D.N. Robinson and S.M. Arnold

University of Akron

Akron, Ohio

April 1986

Prepared for

Lewis Research Center

Under Grant NAG 3-379

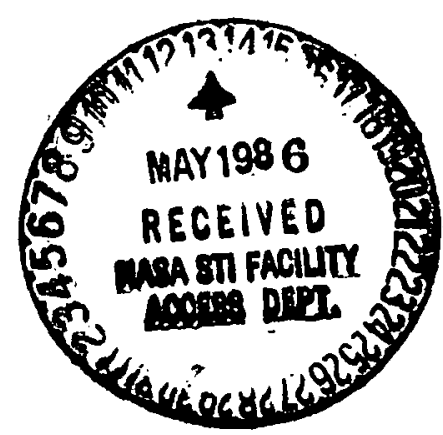


D. N. Robinson*

S. M. Arnoldt*

$\therefore$

ABSTRACT

Structural alloys embody internal mechanisms that allow recovery of state with varying stress and elevated temperature, i.e., they can return to a softer state following periods of hardening. Such material behavior is known to strongly influence structural response under some important thermomechanical loadings, for example that involving thermal ratchetting. Here, we investigate the influence of dynamic and thermal recovery on the creep buckling of a column under variable loading. The column is taken as the idealized (Shanley) sandwich column. The constitutive model, unlike the comionly employed Norton creep model, incorporates a representation of both dynamic and thermal (state) recovery. The material parameters of the constitutive model are chosen to characterize Narloy $Z$, a representative copper alloy used in thrust nozzle liners of reusable rocket engines. Variable loading histories include rapid cyclic unloading/reloading sequences and intermittent reductions of load for extended periods of time; these are superimposed on a constant load. The calculated results show that state recovery significantly affects creep buckling under variable loading. Failure to account for state recovery in the constitutive relations can lead to nonconservative predictions of the critical creep buckling time.

* Professor, Department of Civil Engineering, University of Akron, Akron, Ohio, 44325 and NASA Lewis Research Center.

** Graduate Student, Department of Civil Engineering University, University of Akron, Akron, Ohio 44325. 


\section{INTRODUCTION}

The influence of dynamic and thermal recovery on the high temperature behavior of structural alloys is well recognized [1,2] (see Figs. 1 and 2). For example, recovery is believed to play a major role in one of the central structural problems relating to liquid metal breeder reactor design, the problem of thermal ratchetting. Failure to account for recovery effects in structural analyses involving repeated thermal transients has been shown to give qualitatively incorrect and nonconservative predictions of ratchetting in some instances [3]. Special provisions for taking recovery into account (e.g., the so called $\alpha$-reset procedure) [4] are now finding their way into documents for guiding structural analys is in the U.S. nuclear industry. The effects of thermal ratchetting have also been observed in thrust nozzle liners of reusable rocket engines.

A second area in which recovery effects are thought to play a primary role, and one that impacts essentially all high temperature system design, is that of creep crack growth under creep/fatigue (variable stress) conditions. Creep (state) recovery is believed to be one of the main causes of acceleration of crack growth in the creep regime and under variable loads. A study by Kubo [5], using the same constitutive relations [2,6] employed in the present work, has shown that the experimentally observed acceleration of creep cracks under variable stress can be predicted through the inclusion of appropriate mechanisms of recovery in the constitutive relations.

In this paper we discuss a third area of mechanics in which recovery is expected to have significant influence, that is the problem of creep buckling under variable loading. The presence of mechanisms of recovery 
can allow creep strain rates to increase following periods of hardening and thus cause acceleration of creep buckling. Load reversals may be accompanied by dynamic recovery as in fig. 1 and load reductions by thermal recovery as in Fig. 2; in either case, creep rates are increased upon reloading, tending to reduce the critical time to buckling.

In the vast majority of creep buckling studies the constitutive model used has been of the Norton type [7-9] in which the (steady state) creep rate is taken as a function of stress and temperature alone. Some investigations have made use of hardening theories [10-12] that include a primary creep phase. However, these theories do not generally allow for inelastic state recovery and, consequently, for rejuvenation of primary creep. These constitutive theories are adequate in the case of constant loading but may significantly over predict the time to buckling under certain types of variable loading.

Here, we examine the elevated temperature creep buckling problem under variable loading using the simple Shanley model [13] of a column but with a constitutive model $[2,6]$ that embodies a representation of both dynamic and thermal recovery. The constitutive model is that developed principally by Robinson at Oak Ridge National Laboratory and NASA Lewis Research Center and, as indicated earlier, was that used in the studies concerning creep crack growth by Kubo.

The present study was motivated partly by the occurence of what appears to be local ratchetting-buckling failures in the throat liner of the main thrust nozzles of reusable rocket engines, notably the NASA Space Shuttle main engine. For that reason the material parameters used in the constitutive equations are chosen to represent a copper alloy, Narloy - $Z$, which is typical of materials used in rocket engine thrust nozzle liners. 
We shall first state the constitutive model and, secondly, specify the geometry of the Shanley column model. We then investigate creep buckling behavior under constant loading; cyclic loading which includes relatively. rapid load reductions and reversals (dynamic recovery); and cyclic loading which includes intermittent reductions of load for extended periods of time (thermal recovery). Some of the calculations are repeated for comparison using a roughly equivalent Norton type creep model. A discussion is given of some physical aspects associated with the constitutive model and the results and finally, we state the conclusions drawn from the study.

\section{THE CONSTITUTIVE THEORY}

As indicated earlier we make use of the constitutive law reported in $[2,6]$ where a complete multiaxial statement of the model is given. Here, we state the model in uniaxial terms together with the corresponding parameter values appropriate for the copper alloy Narloy-z.

Flow Taw:

$$
\stackrel{p}{e}= \begin{cases}A F^{n} \operatorname{sgn}(\sigma-\alpha) ; & F>0 \text { and } \sigma(\sigma-\alpha)>0 \\ 0 \quad & ; F<0 \text { or } F>0 \text { and } \sigma(\sigma-\alpha)<0\end{cases}
$$

Evolutionary law:

$$
\dot{\alpha} \therefore=\left\{\begin{array}{l}
\frac{H}{|\alpha|^{\beta}} \dot{e}^{p}-R|\alpha|^{m-\beta} \text { sgna; } \alpha>\alpha \text { and } \sigma \alpha>0 \\
\frac{H}{\alpha_{0}^{\beta}} \dot{\varepsilon^{p}}-R \alpha_{0}^{m-\beta} \operatorname{sgn} \alpha ; \alpha<\alpha_{0} \text { or } \sigma \alpha<0
\end{array}\right.
$$




$$
\text { in which } \quad \begin{aligned}
F & =\frac{(\sigma-\alpha)^{2}}{k^{2}}-1 \\
& A=1.60 \times 10^{-8} \\
n & =4 \\
m & =8.73 \\
B & =1.07 \times 10^{-6}\left(T^{2}\right)+1.60 \\
k^{2} & =209.6-0.20(T) \\
H & =1.46 \times 10^{7} \\
R & =1.06 \times 10^{-7} \\
\alpha_{O} & =0.2
\end{aligned}
$$

$\dot{\varepsilon}^{p}$ indicates the inelastic strain rate in $h^{-1}$ and $\sigma$ the applied uniaxial stress in MPa. In the general form of the theory, $k$ (MPa) is a BinghamPrager threshold stress playing the role of a scalar state variable, here it is taken to have the constant value given above. For present purposes, $\alpha$ (MPa) is the single inelastic state variable. It represents the uniaxial component of a tensorial state variable (internal stress) that appears in the multiaxial formulation of the theory. $\alpha_{0}$ is the minimum attainable value of $|\alpha|$ and plays a primary role in the representation of dynamic recovery (see Discussion). The remaining paraneters, in some cases functions of temperature (T), are consistent with the units MPa, $h$ and degrees Kelvin. The elastic response is characterized by a linearly temperature dependent Young's modulus $E^{\prime}(M P a)$ given by

$$
E=1.47 \times 10^{5}-70.5(T)
$$


Equations (1-4) incorporate both dynamic and thermal recovery and therefore are capable of predicting the type of behavior illustrated in Figs. (1) and (2).

The parameter values for Narloy - $Z$ were determined from uniaxial tensile and stress relaxation test data. As the complete data base normally required to characterize a particular alloy using the present constitutive theory was not available the tensile and relaxation data had to be considered sufficient.

Tensile data were found [14] over a wide temperature range ( $30-811 \mathrm{~K})$ but at only a single strain rate $0.002 / \mathrm{s}$. Limited stress relaxation data [15] were found at the temperature $811 \mathrm{~K}$ (1000F); these were used in the absence of creep data. The most serious data deficiency in the present context concerns the lack of tests giving a direct measurement of recovery effects, i.e., tests such as strain or stress transient dip tests or open loop cyclic tests involving partial stress reversals. Nevertheless, it is believed that the material characterization is adequate for a reasonably quantitative study of creep buckling behavior under variable stress.

Figure 3 shows a comparison of the tensile data with predictions based on equations (1) - (4). Figure 4 gives a similar comparison of typical relaxation responses with a prediction. Neither figure is intended as a demonstration of the predictive capability of the constitutive model but simply as an assessment of the correlation with existing data. The predictive capability of the constitutive theory has been adequately demonstrated relative to other alloys in earlier publications $[2,6]$. 
THE SHANLEY COLUMN

The column model adopted here is the sandwich idealization introduced by Shanley [13] and used by Kachanov [16] and others. The column geometry is indicated in Fig. 5. All of the deformation is presumed to occur in the slender bar elements 1 and 2 of length $h$ and cross sectional area $A / 2$. The remainder of the column of length $L(L>>h)$ remains rigid. The width of the column, i.e., the distance separating bars 1 and 2 , is also taken as $h$.

The column is loaded by a time dependent load $P(t)$ (shown positive); the lateral displacement of the load point at any time is denoted by $u(t)$. The stress and total strain in bars 1 and 2 are denoted by $\sigma_{1}, \sigma_{2}$ and $e_{1}=\delta_{1} / h$ and $e_{2}=\delta_{2} / h$, respectively.

Equilibrium requires that

$$
\sigma_{2}+\sigma_{1}=2 \sigma_{0}
$$

and

$$
\sigma_{2}-\sigma_{1}=\frac{4 \sigma_{0} u}{h}
$$

where $\sigma_{0}=P / A$.

Differentiation with respect to time provides the rate form of the equilibrium equations,

$$
\dot{\sigma}_{2}+\dot{\sigma}_{1}=2 \dot{\sigma}_{0}
$$

and

$$
\dot{\sigma}_{2}-\dot{\sigma}_{1}=\frac{4 u}{h} \dot{\sigma}_{0}+4 \sigma_{0} \frac{\dot{u}}{h}
$$

From geometrical considerations (Fig. 5) the compatibility condition is obtained as 


$$
\frac{\delta_{1}-\delta_{2}}{h}:=\frac{u-u_{0}}{L}
$$

or

$$
e_{1}-e_{2}=\frac{u-u_{0}}{L}
$$

in which $u_{0}$ is the initial displacement (imperfection). The rate form of the compatibility relation is

$$
\dot{e}_{1}-\dot{e}_{2}=\frac{\dot{u}}{L}
$$

Decomposing the total strain rates in each bar into elastic and inelastic contributions gives

$$
\begin{aligned}
& \dot{e}_{1}=\frac{\dot{\sigma}_{1}}{E}+\dot{\varepsilon}_{1}^{p} \\
& \dot{e}_{2}=\frac{\dot{\sigma}_{2}}{E}+\dot{\varepsilon}_{2}^{p}
\end{aligned}
$$

where $E$ is the Young's modulus as specified in equation (5). The inelastic strain rates $\dot{\varepsilon}_{1}^{p}$ and $\dot{\varepsilon}_{2}^{p}$ are, of course, obtained by applying the inelastic constitutive equations (1) - (4) to each bar.

Combining the equilibrium equations (8) and (9), the compatibility. equation (12), and the constitutive relationships (13) and (14) leads to

$\therefore \quad \dot{\sigma}_{1}\left(1+\frac{4 L}{E h} \sigma_{0}\right)=\dot{\sigma}_{0}\left(1+\frac{4 L}{E h} \sigma_{0}-\frac{2 u}{h}\right)-\frac{2 L}{h} \sigma_{0}\left(\dot{\varepsilon}_{1}^{p}-\dot{\varepsilon}_{2}^{p}\right)$ 
Under constant compressive stress (i.e., $\sigma_{0}<0$ and $\dot{\sigma}_{0}=0$ ), and in the absence of inelasticity $\left(\dot{\varepsilon}_{1}^{\cdot p}=\varepsilon_{2}^{\cdot p}=0\right)$, equation (15) gives the Euler critical stress for the idealized column as

$$
\sigma_{c}=\frac{E h}{4 L}
$$

Further, calling

$$
\rho=\frac{\sigma_{0}}{\sigma_{C}}
$$

and

$$
n=\frac{2 u}{h}
$$

where $n$ is termed the nondimensional displacement, we have from equation (15)

$$
\dot{\sigma}_{1}=\frac{\dot{\sigma}_{0}}{1+\rho}[1+\rho-n]-\frac{\rho}{1+\rho} \frac{E}{2}\left(\dot{\varepsilon}_{1}^{p}-\dot{\varepsilon}_{2}^{p}\right)
$$

Now, from equation (6)

$$
\dot{\sigma}_{2}=2 \dot{\sigma}_{0}-\dot{\sigma}_{1}
$$

and from equations (12), (13), (14) and (18)

$$
\dot{n}=\frac{E}{2 \sigma_{c}}\left(\frac{\dot{\sigma}_{1}}{E}+\dot{\varepsilon}_{1}^{p}-\frac{\dot{\sigma}_{2}}{E}-\dot{\varepsilon}_{2}^{p}\right)
$$

The coupled system of equations (1), (2), (3), (19), (20) and (21) together with the appropriate initial conditions, including the initial imperfection $n_{0}=n(0)$, allow the (nondimensional) displacement $n(t)$ to be calculated for a specified temperature T, Euler critical stress $\sigma_{C}$ and history of loading $\sigma_{0}(t)$. The results of several such calculations for various loading histories are presented in the following section. 
All of the calculated results are isothermal with the temperature taken to be $81 \mathrm{k}$ (1000F). The Euler critical stress $\sigma_{C}$ is $200 \mathrm{MPa}$ and the roading/ unloading ramp rate $\left|\dot{\sigma}_{0}\right|$ is $96 \mathrm{MPa} / \mathrm{sec}$. The governing system of equations was integrated using a self-adapting Adans-Bashforth predictor-corrector method with a 4 th order Runge-Kutta method as a starter. The calculations were performed in double precision on a Prime 850 computer with an upper error bound of $10^{-4}$.

In all cases, the criterion defining the critical time to buckling $t_{c}$ is taken as

$$
n=\frac{2 u}{n}=1
$$

This is equivalent, under constant load, to the criterion

$$
\sigma_{1}=0
$$

i.e., the stress in bar element 1 becoming zero.

\section{Behavior Under Constant Load}

In all calculations the compressive load is first applied from zero, where the deforming elements are considered in a virgin state (i.e., $\alpha_{1}=a_{2}=0$ ), to a nominal value of the applied stress $\sigma_{0}=P / A$ of $-35 \mathrm{MPa}$. Thus, with the Euler stress $\sigma_{C}=200 \mathrm{MPa}$ the nominal value of the ratio $\mathrm{p}$ (equation 17) is

$$
\rho=\frac{\sigma_{0}}{\sigma_{c}}=\frac{-35}{200}=-0.175
$$


In this section we present the calculated results for a constant load, i.e., with $\rho$ held constant at the above value. Figure 6 shows the response $n(\tau)$ under these conditions for four different values of initial (nondimensional) displacement $n_{0}=0.02,0.05,0.10$, and 0.2 . The time $\tau=t / t_{0}$ in Fig. 6 is nondimensional, being normalized with respect to the critical time corresponding to $n_{0}=0.02$, i.e., $t_{0}=6 h$.

It is seen in Fig. 6 that the critical time to buckling is reduced by a factor of almost 8 with an order of magnitude increase in the initial displacement.

For the sake of comparison, all subsequent calculations are taken to have the initial imperfection $n_{0}=0.02$ and are presented in terms of the nondimensional time $\tau=t / t_{0}$.

Behavior Under Variable Load

We first consider the effect of rapid load reductions and reversals superimposed on the constant load $\sigma_{0}=-35 \mathrm{MPa}(\rho=-0.175)$. As shown in the inserts of Fig. 7, load interuptions occur at time intervals of $\tau_{0}=0.15$ with varying amplitude. These include reductions (in the tensile direction) of $\sigma_{0}$ to $-20 \mathrm{MPa}$ and to $0 \mathrm{MPa}$ (insert a), to $+20 \mathrm{MPa}$ (insert b), and a complete reversal to $+35 \mathrm{MPa}$ (insert $\mathrm{c}$ ). The calculated effects of these histories on the creep buckling response $n(\tau)$ are shown in the respective curves $a, b$, and $c$ of Fig. 7 .

Curve a corresponds to the loading histories indicated in insert a, i.e. with reductions to $-20 \mathrm{MPa}$ and $0 \mathrm{MPa}$. The response curve for each is identical to that of Fig. 6 for the same initial displacement 0.02 , indicating that no change in the buckling response has occurred. Response curve b corresponds to insert $b$ in which there is a load reversal to $\sigma_{0}=+20 \mathrm{MPa}$. Here, we begin to see a measurable change in the calculated creep buckling response, the 
critical time having diminished from the constant load case by about $10 \%$. Finally, in curve $c$, we observe a reduction of more than $30 \%$ in the time to buckling. This corresponds to the history of insert $c$ where a complete load reversal from $\sigma_{0}=-35 \mathrm{MPa}$ to $\sigma_{0}=+35 \mathrm{MPa}$ occurs at each load interruption. Immediately following each reversal, we see evidence of the reappearance of primary creep. This is attributed to the presence of dynamic recovery (Fig. 1) where creep (or relaxation) is observed to be accelerated with stress reversals - even in the absence of significant reversed inelastic strain. Although, to the knowledge of the authors, these effects have not been observed directly in creep buckling phenomena, it is expected that such effects can occur, on the basis of the experimental observations illustrated schematically in Fig. 1 .

The influence of dynamic recovery is best understood by considering the state space $(\sigma, \alpha)$ of Fig. 8 . Note that in Fig. 8 and all subsequent representations of the state space, compressive $\sigma$ and a are shown as positive and are plotted upward and to the right, respectively. Hereafter, the relevant quadrants of the state space will be referred to as the first. $(\sigma \alpha>0)$ and the fourth $(\sigma \alpha<0)$. In Fig. 8 the trajectory of the state point $\left(\sigma_{2}, \alpha_{2}\right)$ for bar element 2 is shown corresponding to the constant load response curve a in: Fig. 6.: The segment $O A$ traces the path of the state point during initial load-up to $\sigma_{0}=-35 \mathrm{MPa}$. Some inelasticity is indicated over path $O A$ by the increase in the inelastic state variable $\alpha_{2}$. As $\sigma_{0}$ is held constant, bar 2 creeps under nearly constant stress and the state point moves toward B. As the geometric nonlinearity becomes prevalent the stress in bar 2 increases (as: that in bar 1 decreases) and the state point moves toward $C$. Point $C$ corresponds to the buckled condition $n=1$ in Fig. 6 (curve a). 
Similarly, Fig. 9 shows the trajectory of the state point for the loading: histories illustrated in insert a of Fig. 7, i.e., involving load reductions to $\sigma_{0}=-20 \mathrm{MPa}$ and to $\sigma_{0}=0$. Here, we see the effect of the abrupt load changes as vertical (elastic) trajectories in the state space, resulting in no overall change in the state path $O A B C$ from that just considered for a constant load. This, of course, results in the same creep buckling response observed earlier for the constant load.

The state path of Fig. 10 relates to the loading history of insert $b$ in Fig..7. Here, we begin to see evidence of state recovery. The load variations now produce stress reversals in bar 2 and the state point trajectories are not just vertical (elastic) lines as before, but now follow curved paths as the state point penetrates into the fourth quadrant $(\sigma \alpha<0)$ corresponding to a reversal of stress. The state recovers with the stress reversal, resulting in a relatively softer state (smaller $\alpha_{2}$ ) upon reloading. Correspondingly, the creep rate is increased in response to each load cycle. Evidence of increased creep rate following reloading is apparent in curve b(Fig. 7 ).

Load histories involving larger stress reversals produce increased state recovery. Figure 11 shows the state path in bar 2 for the fully reversed load depicted in insert c (Fig. 7). Here, the effect of dynamic recovery at each unloading/reloading cycle returns the state point well back into the primary creep regime. As observed earlier, clear evidence of the rejuvenation of primary creep after each loading cycle is seen in curve $c$, with the total effect of diminishing the critical buckling time by about $30 \%$.

As the period of application of the rapid loading cycles $\left(\tau_{0}=0.15\right.$ ) was chosen quite arbitrarily, we now investigate the effect of the frequency of load cycles. Figure 12 shows the buckling response curves $n(\tau)$ for load 
histories involving a full reversal, i.e., $\sigma_{0}=-35 \mathrm{MPa}$ to $\sigma_{0}=+35 \mathrm{MPa}$ (as in insert C Fig. 7), with periods $\tau_{0}, \tau_{0} / 2, \tau_{0} / 4$ and $\tau_{0} / 8$ (the constant load response curve is also shown for reference). We see the pronounced effect of more frequent (shorter period) stress reversals. Reversals with period $\tau_{0} / 8$ reduce the time to buckling by more than a factor of 3 .

Next, we examine the influence of load reductions of extended duration on the creep buckling time. The loading histories considered are shown in the inserts of Fig. 13. Case a (i.e., insert a and response curve a) amounts to one of those considered previously (insert a of Fig. 7) where the time duration at the reduced load $\sigma_{0}=0$ is effectively zero. This history, as noted earlier, produces no change in the buckling response over the constant load case.

Insert $b$ depicts the history where the load, having been applied for period $\tau_{0}$, is abruptly removed (at a rate $\left|\dot{\sigma}_{0}\right|=96 \mathrm{MPa} / \mathrm{sec}$ ) and held at zero for a comparable period $\tau_{0}$. The sequence is then repeated. This history reduces the critical time as shown in curve b, by about 15\%. Here, the time $\tau$ includes only that time in which the load $\sigma_{0}=-35 \mathrm{MPa}$ is applied.

As before, this behavior is best visualized in the state space $\left(\sigma_{2}, \alpha_{2}\right)$, Fig. 14. State recovery is observed as, in time, the state point moves at zero stress toward smaller $\alpha_{2}$, e.g., on the first load reduction, from point $D$ to $E$. Reloading returns the state point to a softer state than before the load reduction and correspondingly to a higher creep rate. Repetition of the sequence thus causes acceleration of the creep buckling process.

Insert $c$ of Fig. 13 shows a loading history in which the time at zero stress is now increased a hundredfold to $100 \tau_{0}$. The corresponding response curve $c$ shows a further decrease in the critical time, here about $30 \%$. The related state point trajectory shown in Fig. 15 is qualitatively similar 
to that of Fig. 14 but now shows significantly increased recovery with the hundredfold increase in hold time at the reduced stress.

\section{Comparison with Predictions by Norton Law}

In this section we compare the results presented above with those for identical loading histories based on a classical creep law of the NortonBailey type, i.e.,

$$
\dot{\varepsilon}^{p}=B \sigma^{N} \operatorname{sgn}(\sigma)
$$

A roughly equivalent representation was obtained by calculating the steady state creep rates for various stress levels using equations (1)-(4) and "fitting" equation (25) to these "data" by choosing optimal values of $B$ and $N$ in a least squares sense. This process yielded the following

$$
\begin{aligned}
& B=2.03 \times 10^{-19} \\
& N=9.375
\end{aligned}
$$

which are consistent with units of $\sigma$ in $\mathrm{MPa}$ and $\dot{\varepsilon}^{\mathrm{p}}$ in $h^{-1}$. Using equation (25), the critical time to buckling corresponding to the constant load case of curve a Fig. 6, turned out to be $t_{0}^{\prime}=7.8 \mathrm{~h}$, slightly greater than the earlier reference $t_{0}=6 \mathrm{~h}$. Thus, in the calculated resuits presented here (i.e., Fig. 16), the nondimensional time $\tau$ is obtained by normalization with respect to $t_{0}^{\prime}$. The time plotted is that for which the load $\sigma_{0}=-35 \mathrm{MPa}$ is applied. On this basis, calculations of creep buckling response $n(\tau)$ for all of the loading histories presented earlier have been included in Fig. 16. As expected, the time to buckling is completely unaffected by any of the variable loading histories. This is because the classical Norton-Bailey respresentation (equation (25)) fails to account for state recovery in any form. 


\section{DISCUSSION}

Dynamic recovery, as illustrated in Fig. 1 and by the state point trajectories of Figs. 10 and 11, is characterized in the present constitutive model through the dual analytical forms of the evolutionary law, equations (2). This description is consistent with the viewpoint of Onat [17] in representing inelastic behavior through the specification of analytically different mathematical forms corresponding to various regions of the state space. Here, different analytical forms are specified depending on whether the state point lies in the first (third) quadrant oa>0 or the fourth (second) quadrant oa<o of the state space. In effect, this permits the state point to rapidly recover upon reversing the stress, even in the absence of significant reversed inelastic strain (Fig. 1). This formulation is intended as an idealization of a physical process whereby the dislocation structure (or the associated structure of internal stress) is abruptly altered with a reversal of the applied stress, because previously immobilized dislocations are remobilized on their slip planes [18]. As the inelastic state variable $\alpha$ is taken as an averaged, phenomenological measure of the dislocation microstructure (or its associated internal stress state), it too should reflect a rapid change as the stress is reversed.

The specific functional form of the first of equations (2) is made in accordance with the experimental results of Mitra and McLean [19]. The second equation (2) can be considered an analytical continuation of the first, evaluated at $\alpha_{0}(\operatorname{small} \alpha)$ in the first quadrant of the state space, into the second quadrant; or with symmetrical response in tension and compression, at $-\alpha_{0}$ in the third quadrant into the fourth quadrant. This amounts to a highly idealized representation of the underlying physical process but, 
nevertheless, captures the essential feature that abrupt microstructural rearrangements occur with stress reversals.

The path of the state point in the fourth quadrant $\sigma \alpha<0$ in Figs. 11 and 12, and thus the extent of recovery, depends on the total strain rate and, critically, on the parameter $\alpha_{0}$. Ideally, $\alpha_{0}$, or more comprehensively a function of $\sigma$ and $\alpha$ replacing it, should be determined from experiments in which the recovery of creep rate or flow stress under stress reversals is measured directly and not inferred indirectly from available monotonic tensile, creep and/or relaxation data as was done here. Nevertheless, the present representation is believed to be adequate and consistent with the objective of demonstrating the strong influence of state recovery in creep buckling. A more comprehensive description of dynamic recovery, in the same spirit as that described, and the relevant experimentation are topics of continuing research. Thermal recovery, as depicted in Fig. 2 and in the state paths shown in Figs. 14 and 15, is manifest in the second (negative) term of the BaileyOrowan evolutionary equations (2). In the applications considered here the state point recovers in time under constant (zero) reduced stress, giving rise to an increased creep rate on reapplication of stress (Fig. 2). Physically, this macroscopic behavior is associated with thermally activated, diffusion controlled microscopic processes such as climb of edge dislocations, allowing dislocations, in time, to bypass immobilizing obstacles, thus producing a softer state (smaller $\alpha$ ). The important material parameters in equations (2) are $R, m$ and $B$. Ideally, these parameters are determined from both creep data and information obtained from stress or strain transient dip tests [6] that provide a direct measurement of thermal recovery. Again, as these data were not readily available for the alloy Narloy- 2 , the pertinent parameters were inferred indirectly from available data. As discussed earlier, this approach 
although not optimal, is considered consistent with the present objectives.

\section{CONCLUSIONS}

We have examined the creep buckling response of an idealized (Shanley) column under some special variable loadings. The two types of loading considered amount to superpositions of the following load sequences on a constant applied load:

1) rapid cyclic unloading/reloading sequences involving stress reversals, and

2) cyclic loading that includes intermittent reductions of load for extended periods of time (at temperature).

Although the sandwich column model used is highly idealized, the constitutive model is quite comprehensive, in as much as it incorporates a representation of dynamic and thermal (state) recovery. There is substantial experimental evidence that many structural al loys embody internal mechanisms at elevated temperature that allow inelastic strain rates to increase (recover) following periods of hardening. In particular, this is believed to be true for the representative copper alloy Narloy- $Z$ characterized here.

The loading sequences examined are not intended to represent prototypical loading histories for any particular structural component; instead, they were chosen to best illustrate the generic influence of both dynamic and thermal recovery on structural behavior in the presence of a creep induced instability. It is expected that qualitatively similar behavior will accompany more realistic variable loading conditions, (and more realistic structures), and that neglect of state recovery effects in such cases will lead similarly to nonconservative predictions of the critical time to creep buckling. 
We now list the conclusions drawn from this study:

- State recovery (dynamic and thermal) can have a significant effect on creep buckling behavior, i.e., on the critical time.

- Failure to account for state recovery in the constitutive equations can lead to nonconservative predictions of the critical buckling time under variable loading.

- A classical Norton-Bailey type creep law as commonly used in creep

$\because$ buckling analyses, does not account for state recovery and therefore may significantly over predict the time to creep buckling under variable loading.

- It is important that constitutive models which are to be used in creep buckling analyses involving variable loading allow for recovery effects, and furthermore, that the characterization tests used for determining the pertinent material parameters include direct measurements of. state récovery: 


\section{REFERENCES}

1 Pugh, C.E. and Robinson, D.N., "Modified Auxillary Procedures for Cyclic Creep and Relaxation," ORNL-5281, 1976, pp. 17-40.

2 Robinson, D.N., et.al, "Constitutive Equations for Describing HighTemperature Inelastic Behavior of Structural Alloys," Proceedings of Specialist Meeting on High-Temperature Structural Design Technology of LMFBRS, IAEA Report IWGFR/11, ApriI 1976, Pp. 44-57.

3 Sartory, W.K., "Analysis of the ORNL Two-Bar Thermal Ratchetting Test SBRI," ORNL-5683, 1980, pp. 9-13.

4 Robinson, D.N., "Additions and Modifications to Constitutive Equations in RDT St andard F9-5T," ORNL-5622, 1979, pp. 2-11.

5. Kubo, S., "Effects of Creep Recovery and Hardening on the Stress and Strain-Rate Fields Near a Crack Tip in Creeping Materials," ElasticPlastic Fracture: Second Symposium, Vol. I - Inelastic Crack Analys is, ASTM STP 803, ASTM, 1983, pp. 1-594, 1-614.

6 Robinson, D.N., and Swindeman, R.W., "Unified Creep/Plasticity Constitutive Equations for $21 / 4 \mathrm{Cr}-1$ Mo Steel at El evated Temperature," ORNL TM-8444, 1982.

7 Hoff, N.J., "A Survey of the Theories of Creep Buckling," Proc. of the Third U.S. Nat. Congr. of Applied Mechanics, ASME, Vol. 3, 1958, pp. 29-49.

8 Hayman, B., "Some Observations on Creep Buckling Analys is," 2nd International Conference on Structural Mechanics in Reactor Technology, VoT. 5, Part. L, Berlin, Germany, 1973, pp. 1-12.

9 Hoff, N.J., "Rules and Methods of Stress and Stability Calculations in the Presence of Creep," Jour. of Applied Mechanics, Vol. 45, 1978, pp. 669-675.

10 Libove, C., "Creep Buckling of Columns," Jour. Aeronautical Sciences, Vol. 19, No. 7, 1952, pp. 459-467.

11. Jahsman, W.E., "Creep Stability of a Column with Coupled Geometric Imperfection and Material Behavior Effects," Creep In Structures, Ed. J. Hult, IUTAM Symposium, Gothenburg, Springer-Verlag, 1970, pp. 360-369.

12 Hoff, N.J., and Levi, I.M., "Short Cuts in Creep Buckling Analysis," Int. J. Solids Structures, Vol. 8, 1972, pp. 1103-1114.

13 Shanley, F.R., Weight-Strength Analys is of Aircraft Structures, Dover, NY, 1960. 
14 Esposito, J.J., and Zabora, R.F., "Thrust Chamber Life Prediction, Vol. 1 - Mechanical and Physical Properties of High Performance Rocket Nozzle Materials," NASA CR-134806, 1975.

15 Conway, J.B., Stentz, R.H., and Berling, J.T., "High-Temperature, LowCycle Fatigue of Copper-Base Alloys for Rocket Nozzles: Part I - Data Summary for Materials Tested, NASA CR-134908, 1975.

16 Kachanov, L.M., Creep Theory, Moscow, 1960.

17 Onat, E.T., "Representation of Inelastic Behavior," Creep and Fracture of Engineering Materials and Structures, Ed. B. Wilshire and D.R.J. Owen, Proc. of International Conf. held at Swansea; Pineridge Press, Swansea, U.K., 1981.

18 Orowan, E., "Causes and Effects of Internal Stresses," Internal Stresses and Fatigue in Metals, General Motors Symposium, Elsevier, Amsterdam, 1959, pp. 59-80.

19 Mitra, S.K., and McLean, D., "Work Hardening and Recovery in Creep," Proc. Roy. Soc. (London) 295(a), 1961, pp. 288-299. 


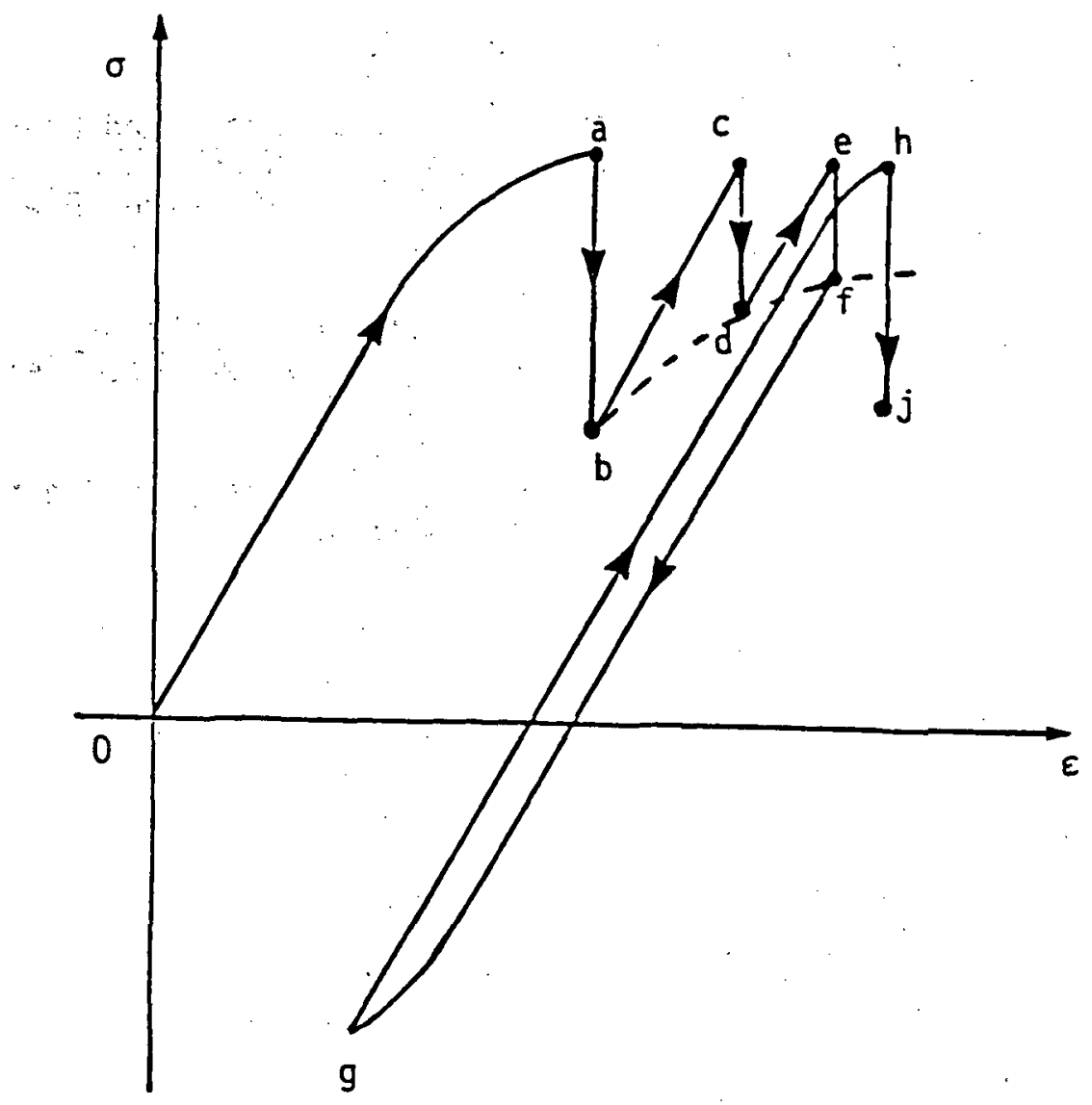

Fig. I Schematic representation of dynamic recovery. In the absence of stress reversals, the stress relaxations over a fixed time $a b, c d$ and ef show successive hardening. After the stress reversal fgh, stress relaxation hj shows evidence of (creep) softening, i.e. evidence of recovery of state (see (I)). 


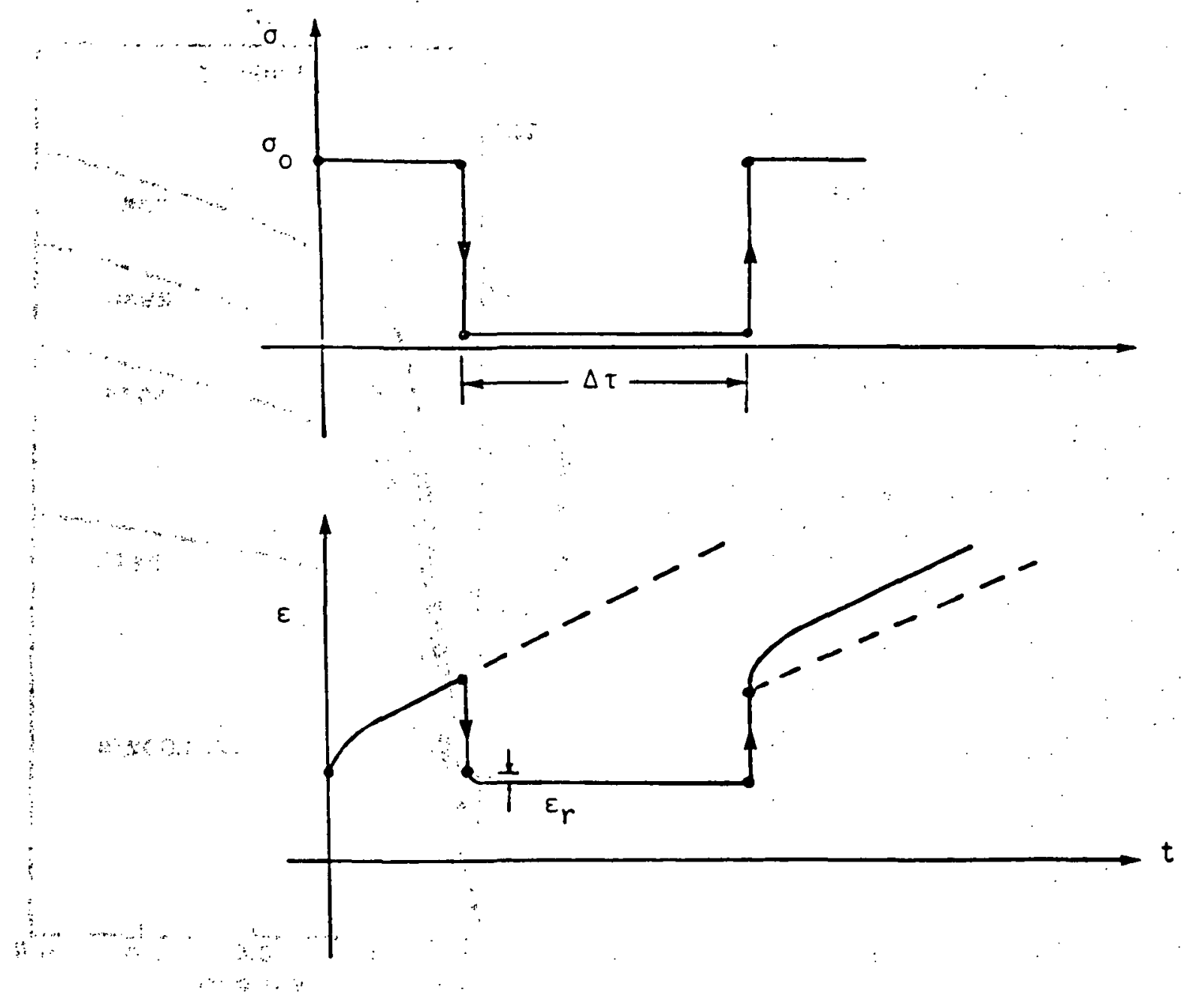

Fig. 2 : Schematic representation of thermal recovery. Response in an interupted creep test typically exhibits relatively shajl strain recovery $\varepsilon_{r}$ but measurable softening ( depending on the interval $\Delta \tau$ ) following a stress reduction, i.e. recoyery of state (see (2)). 

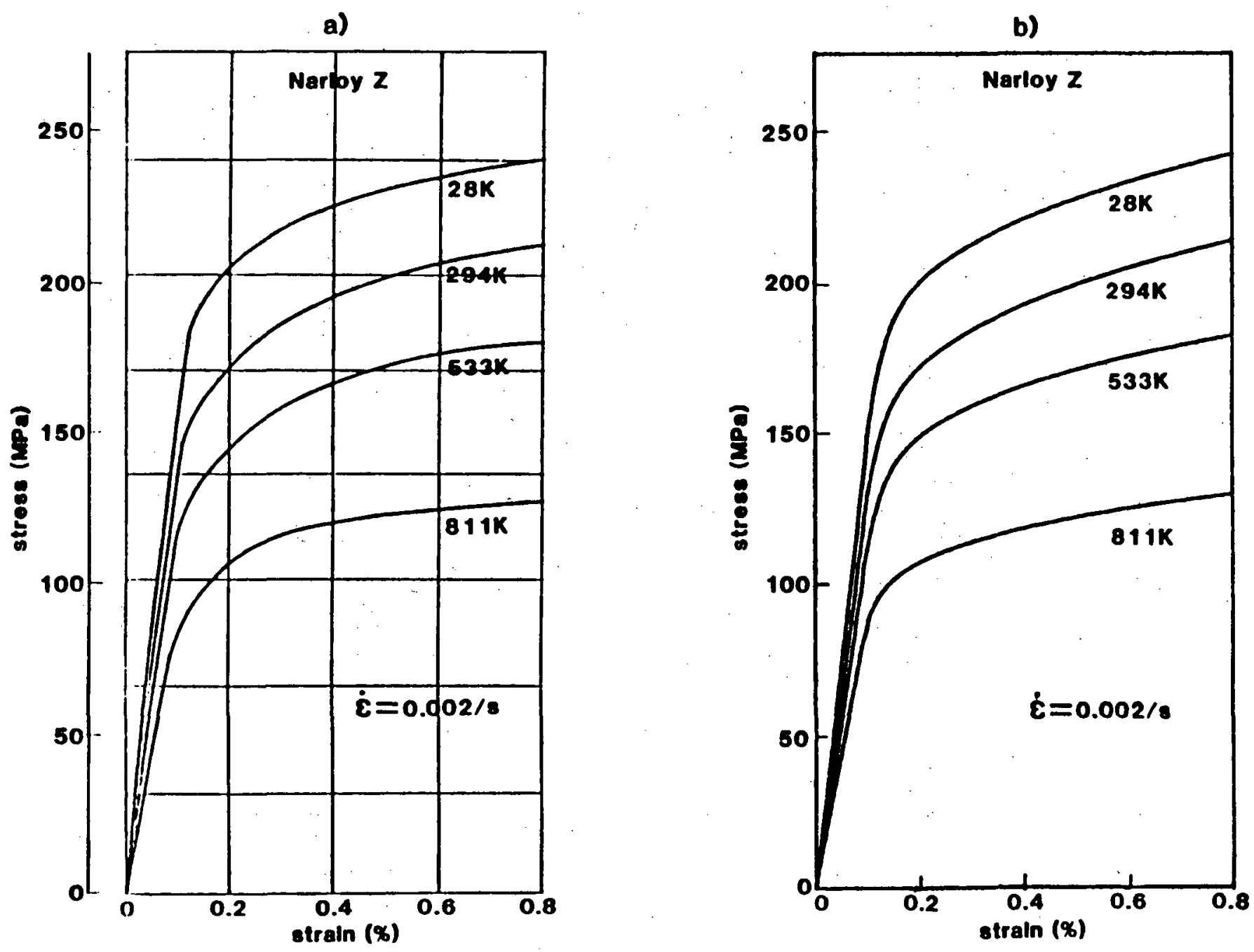

Fig. 3 Comparison of a) tenstle data [14] and, b) predictions for Narloy $Z$ at various temperatures. Strain rate is $.002 / \mathrm{s}$. 


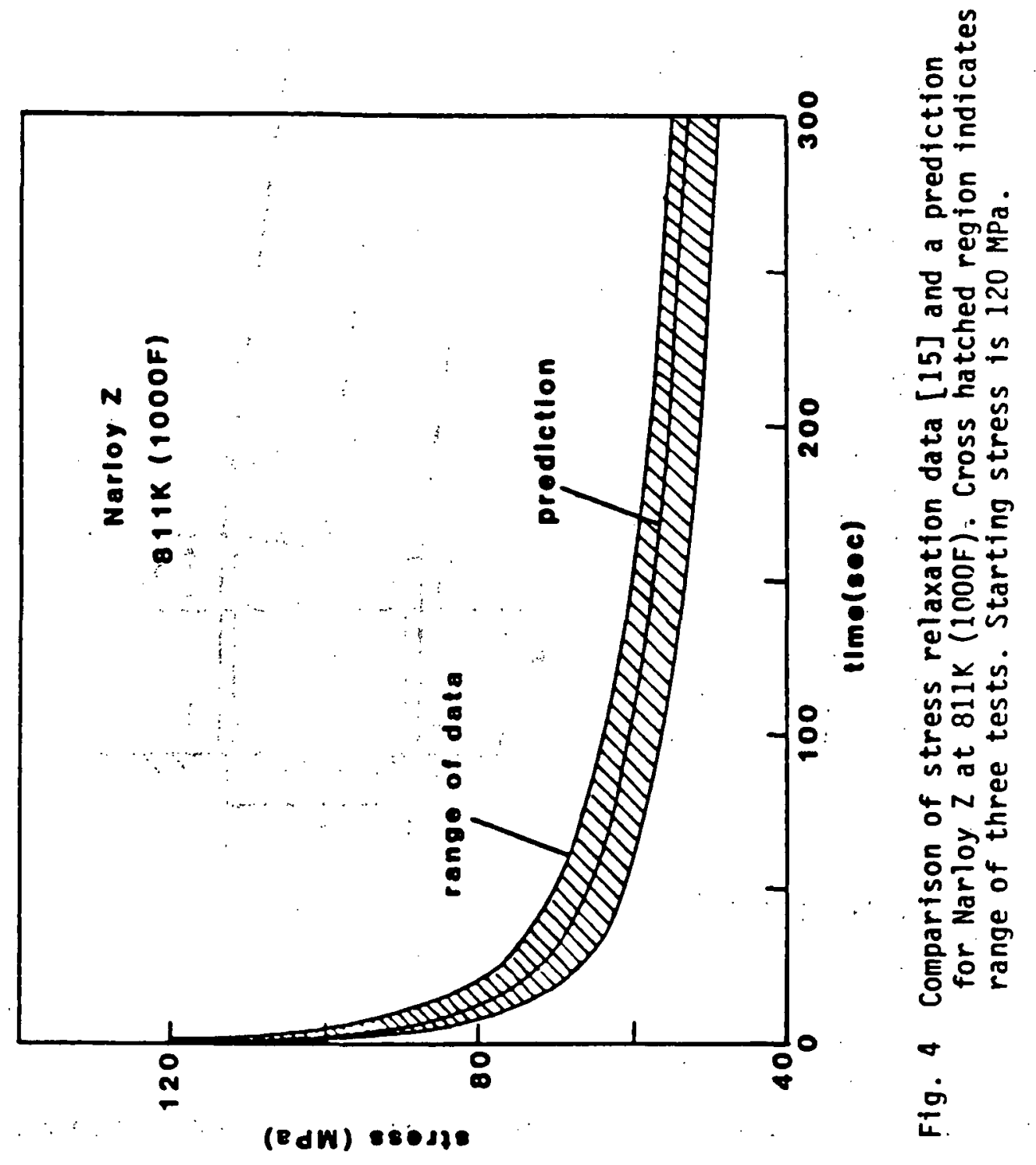




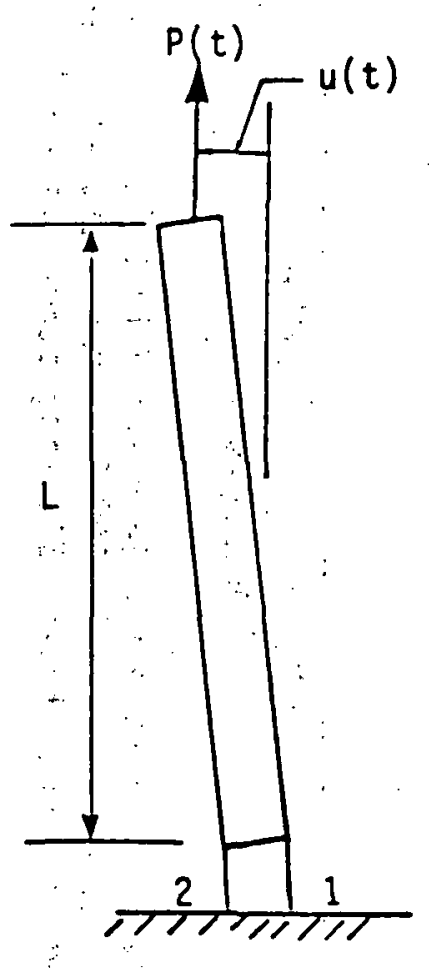

$\because$

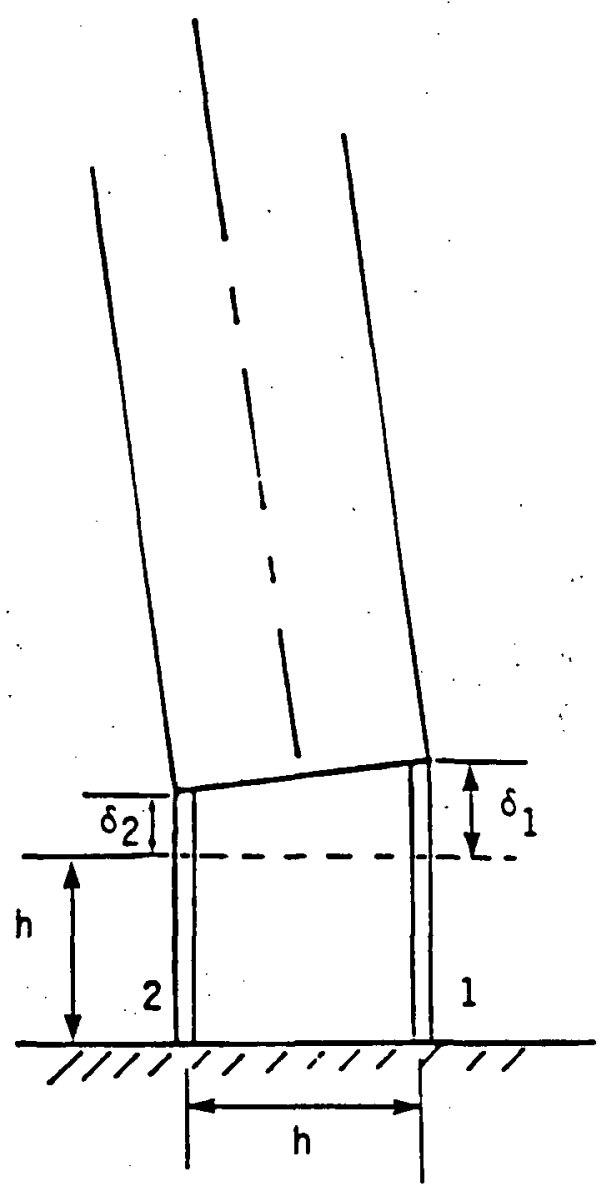

b)

Fig. 5 Georietry of the Shanley, sandwich coluin. 


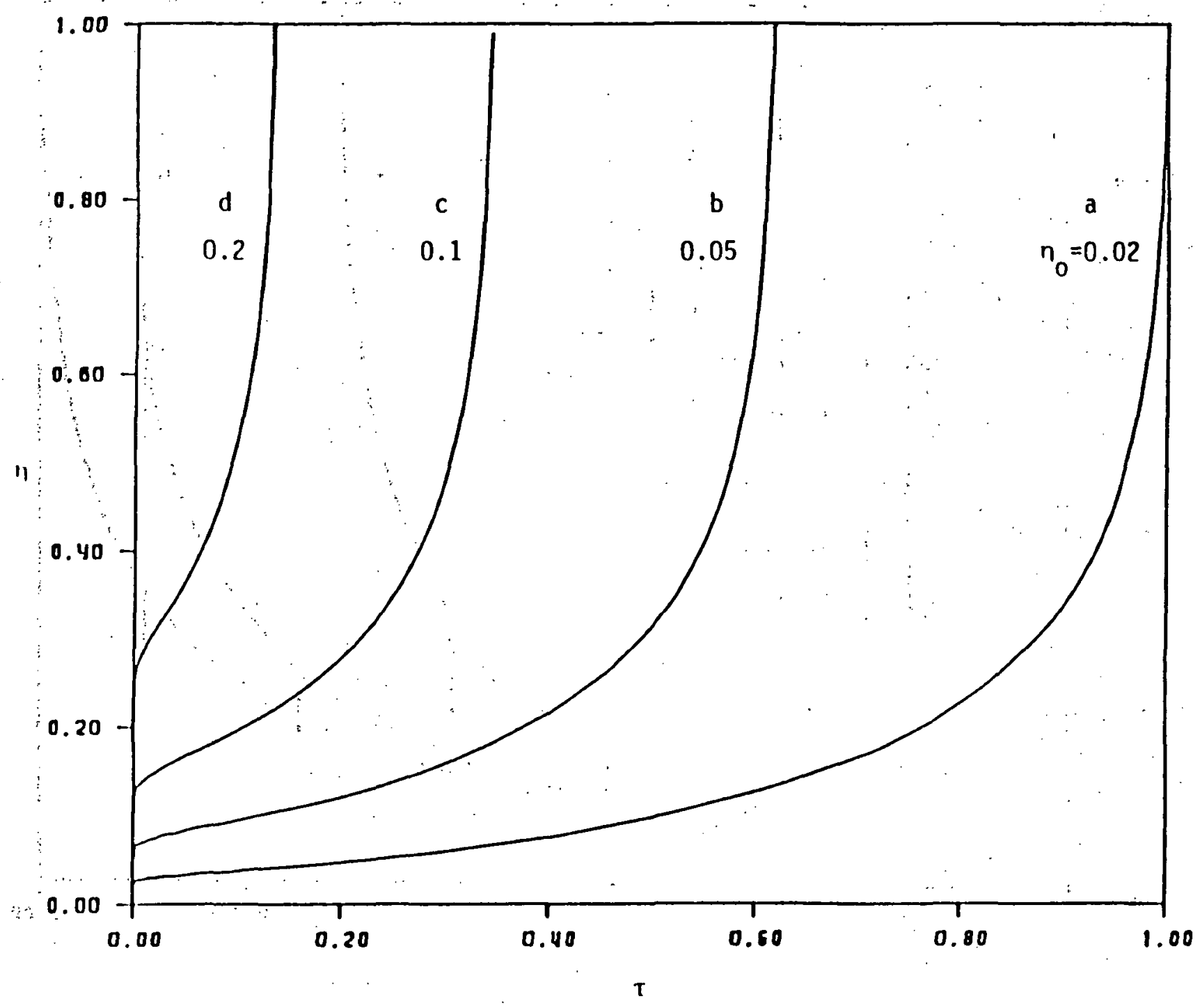

Fig. 6 Nondinensional displacement versus time for initial imperfections of $\eta_{0}=0.02$ (a), 0.05 (b)., 0.1 (c) and 0.2 (d). 


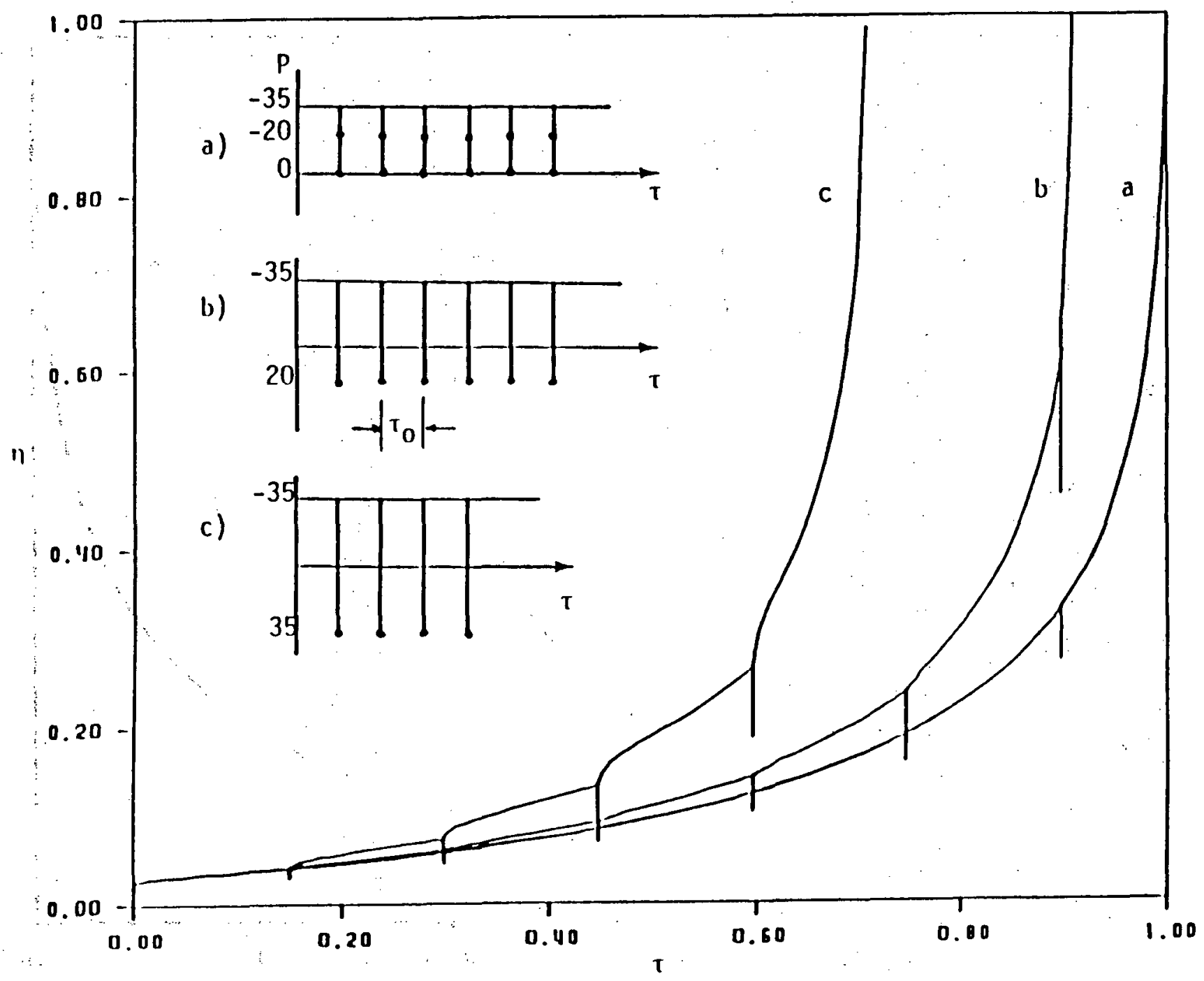

Fig. 7 Nondimensional displacement versus time for loading histories depicted in inserts a),b) and c). 


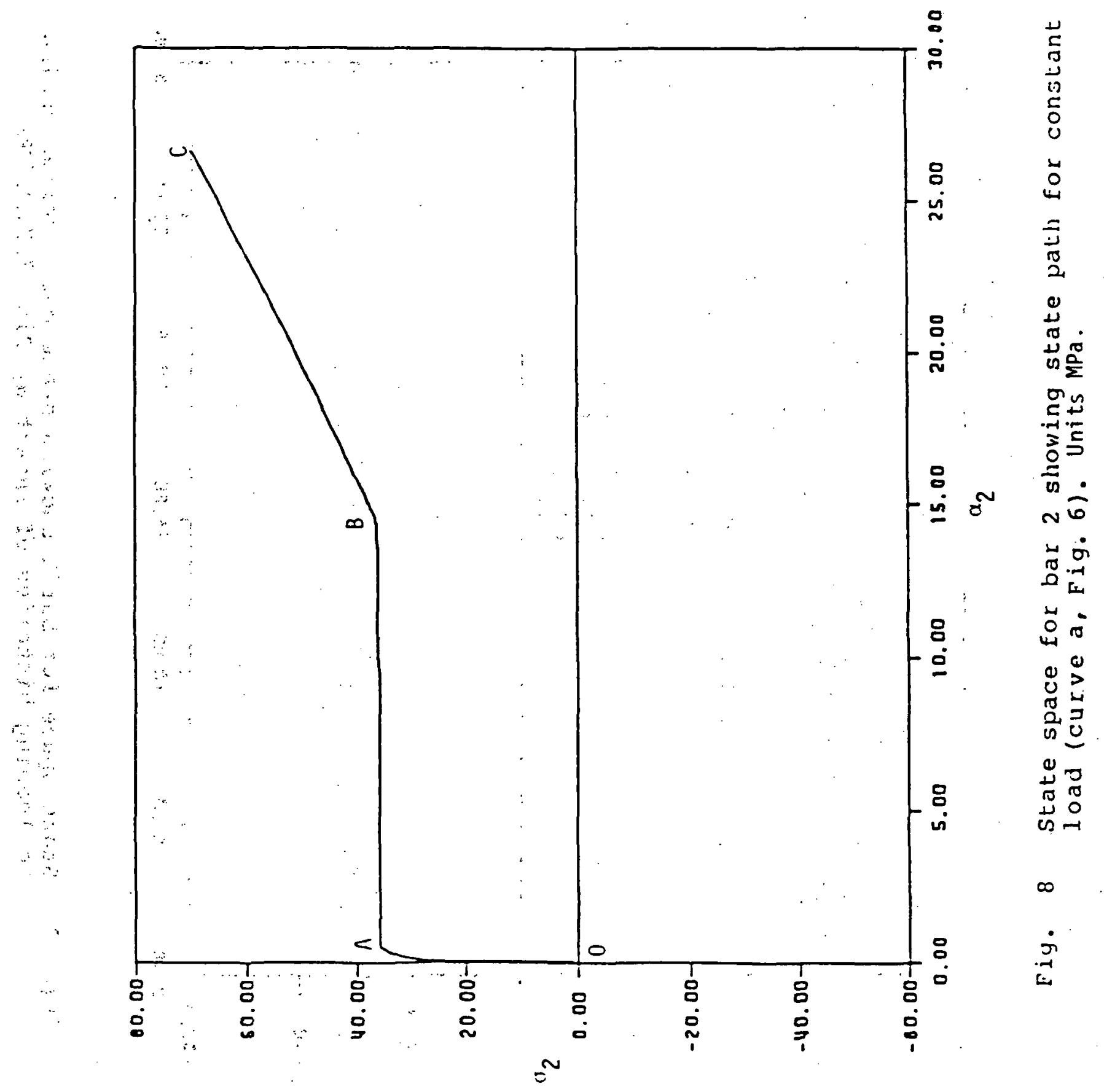




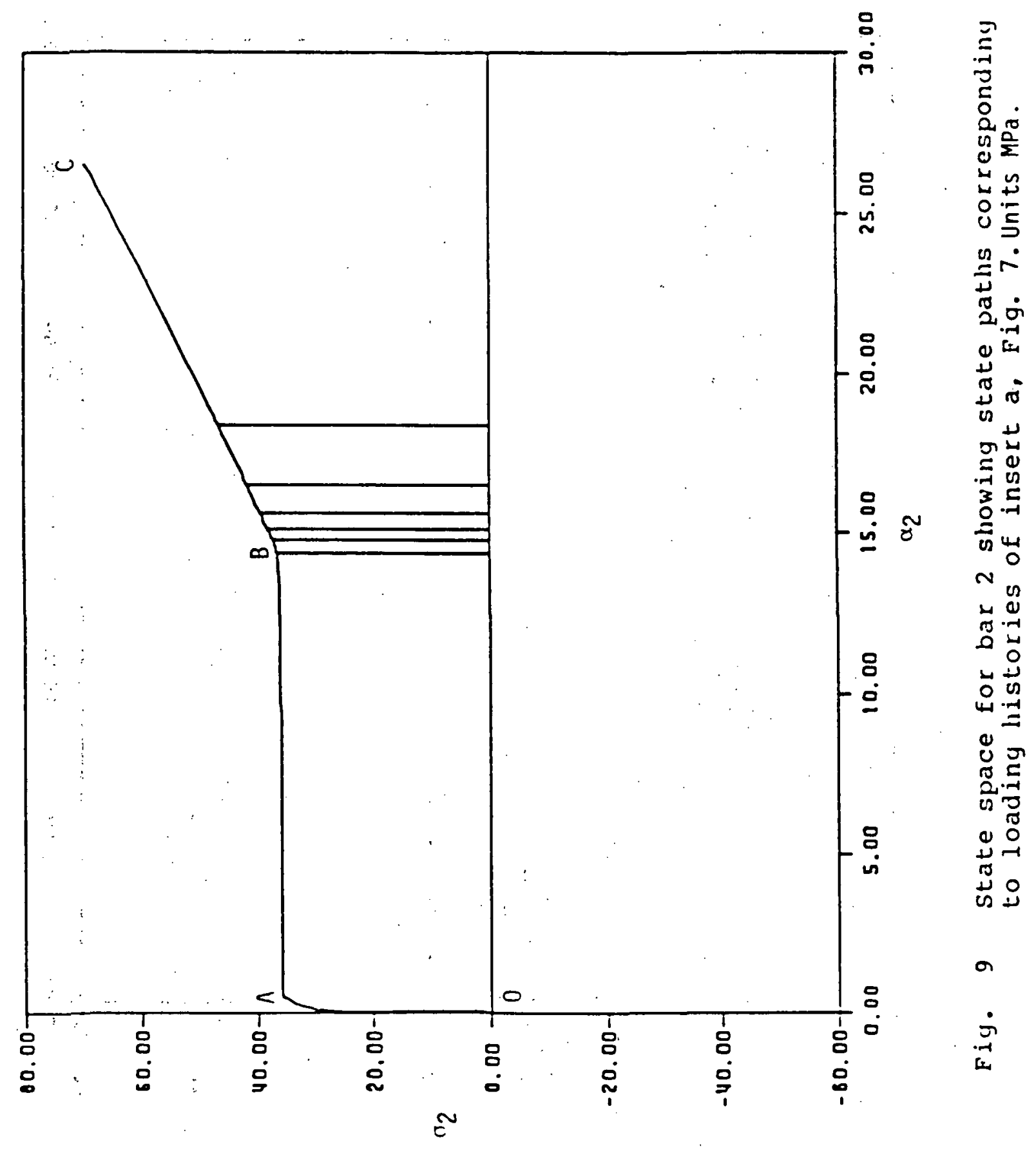




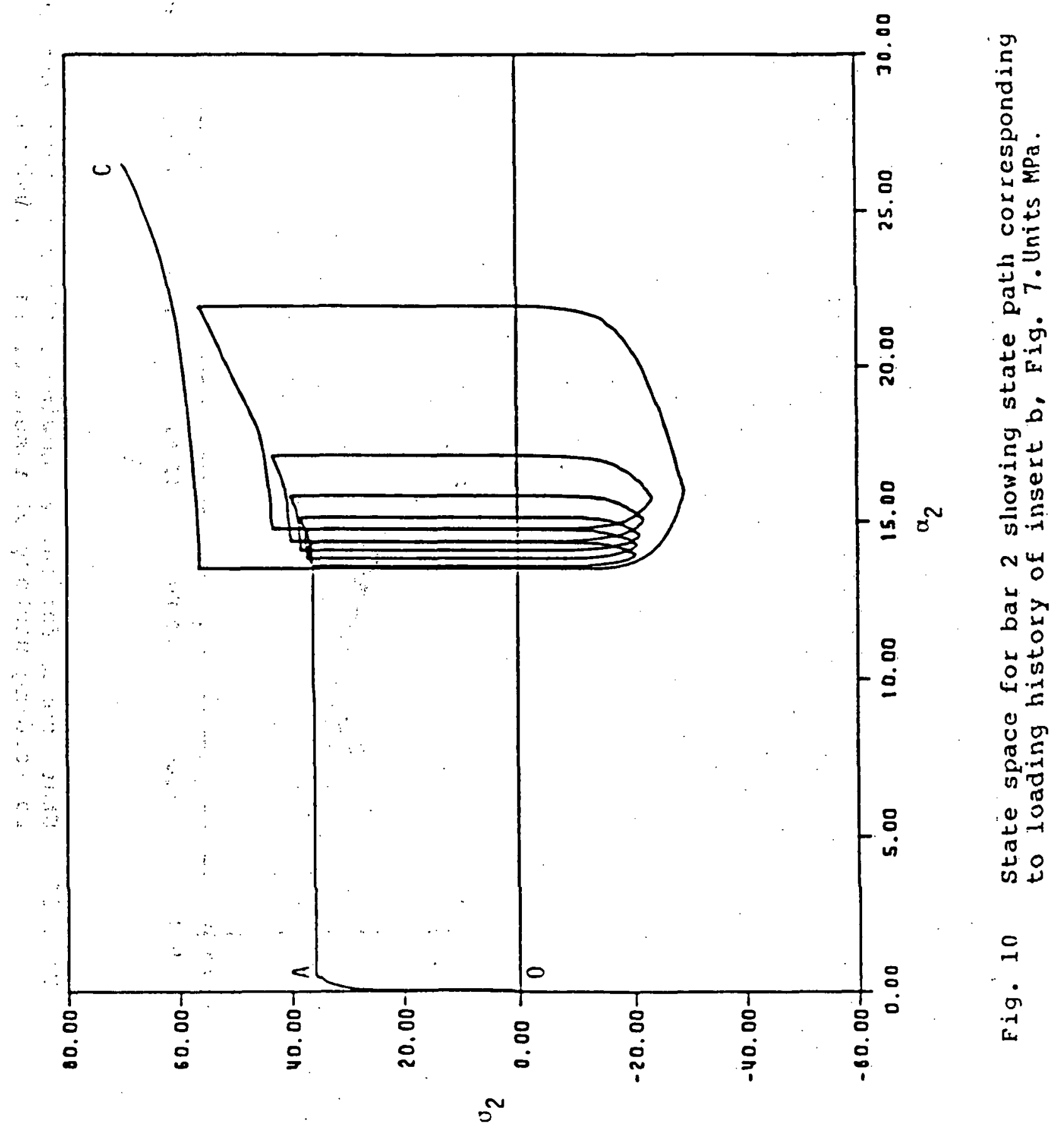




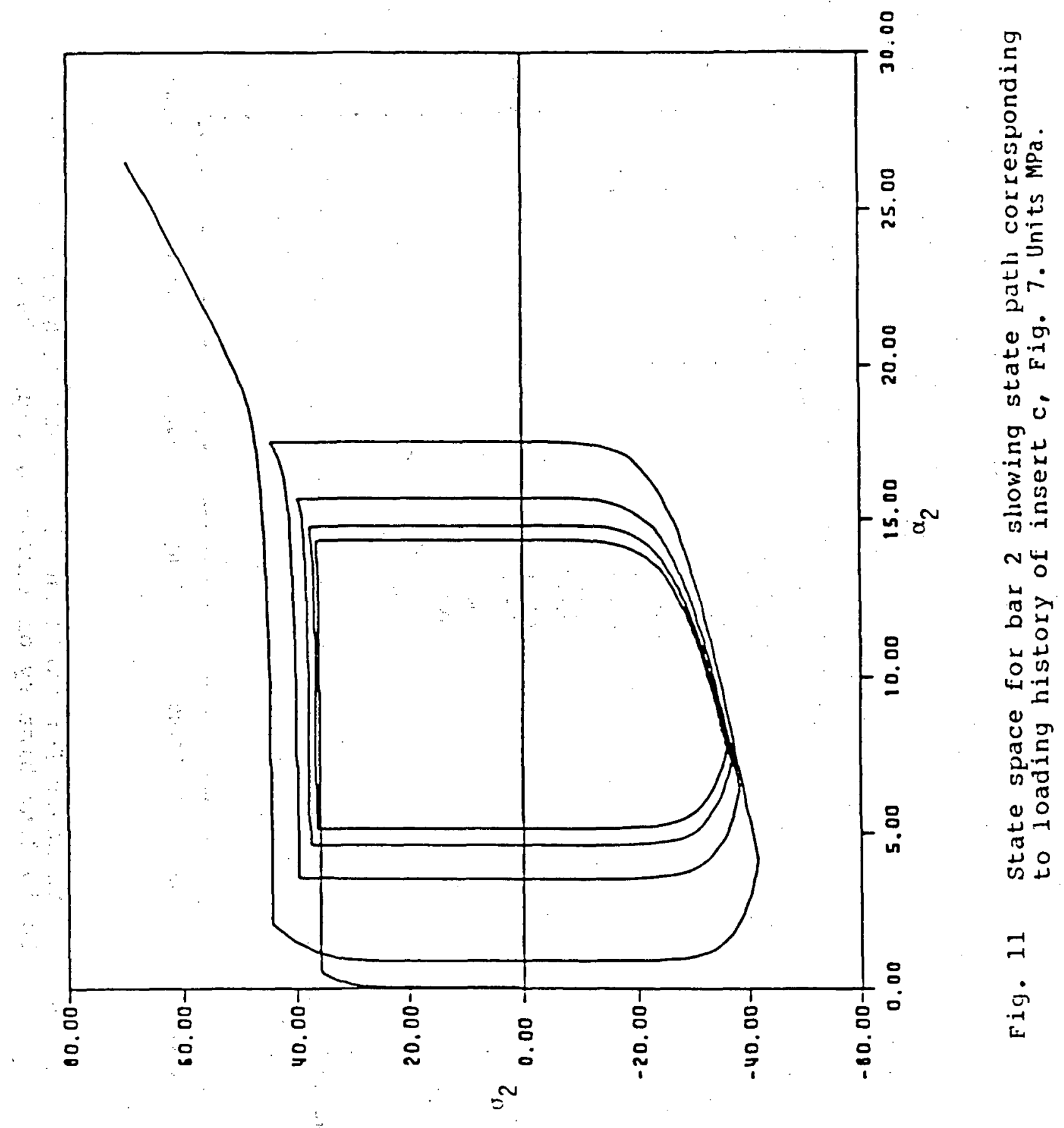




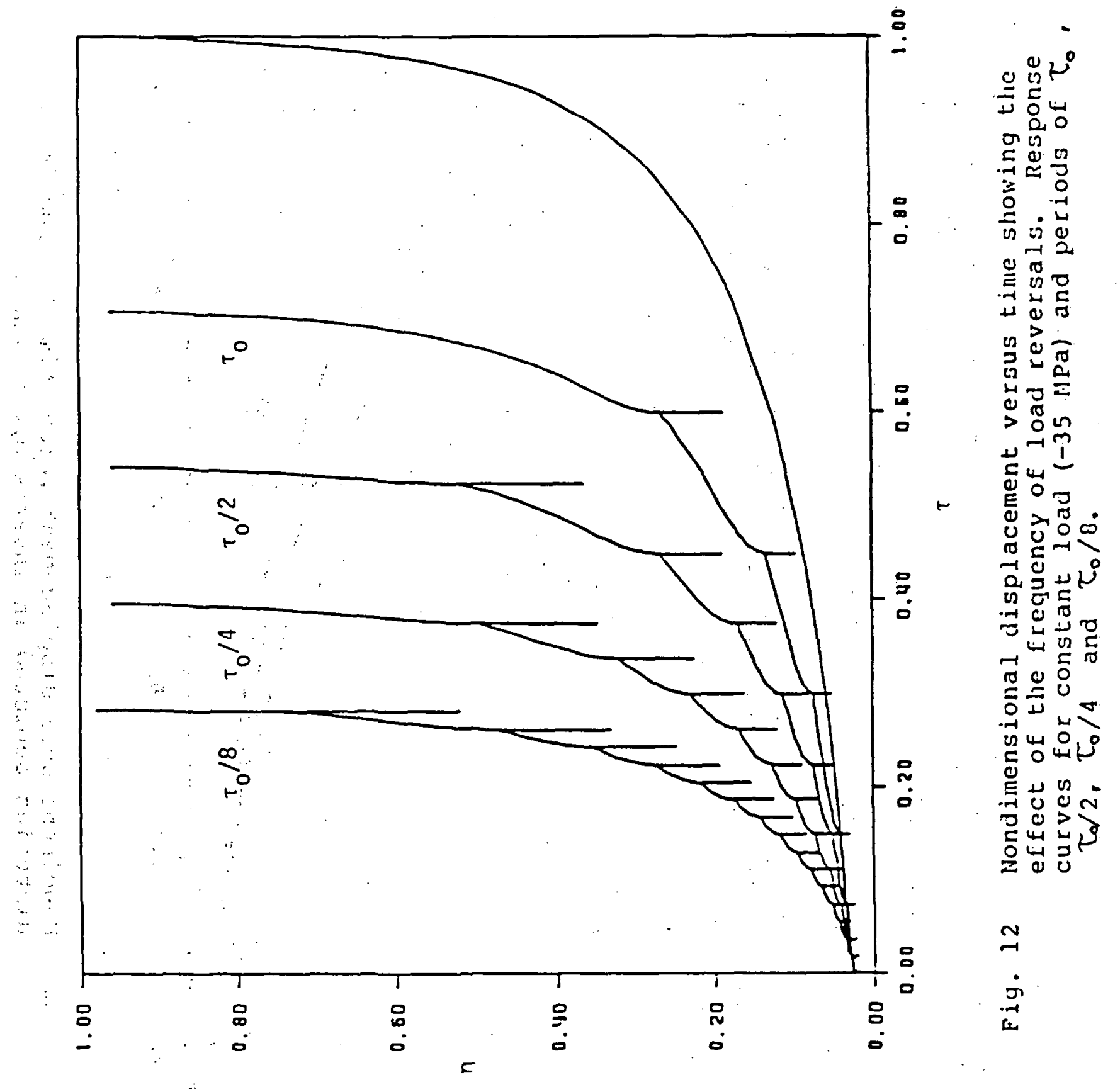




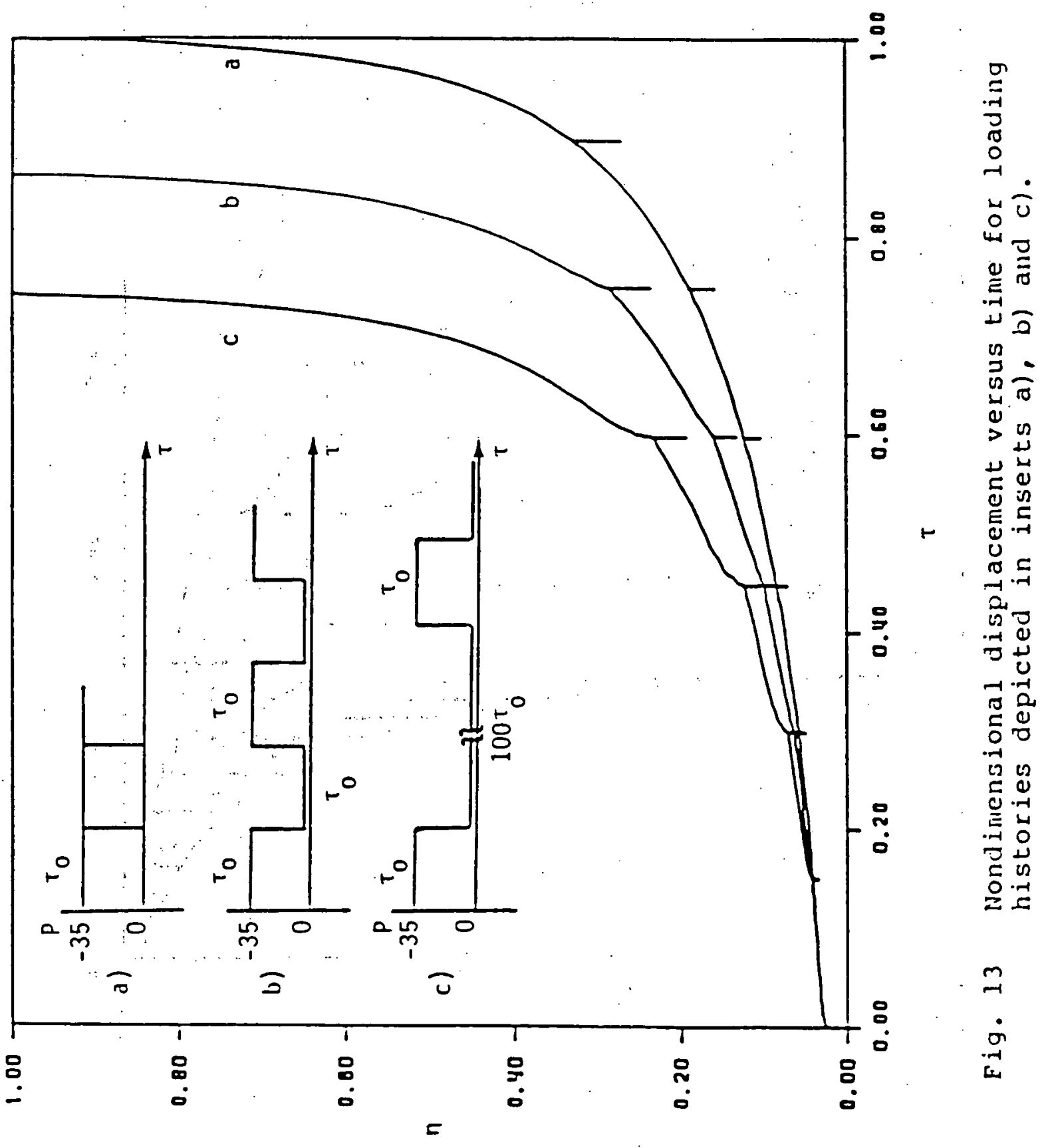




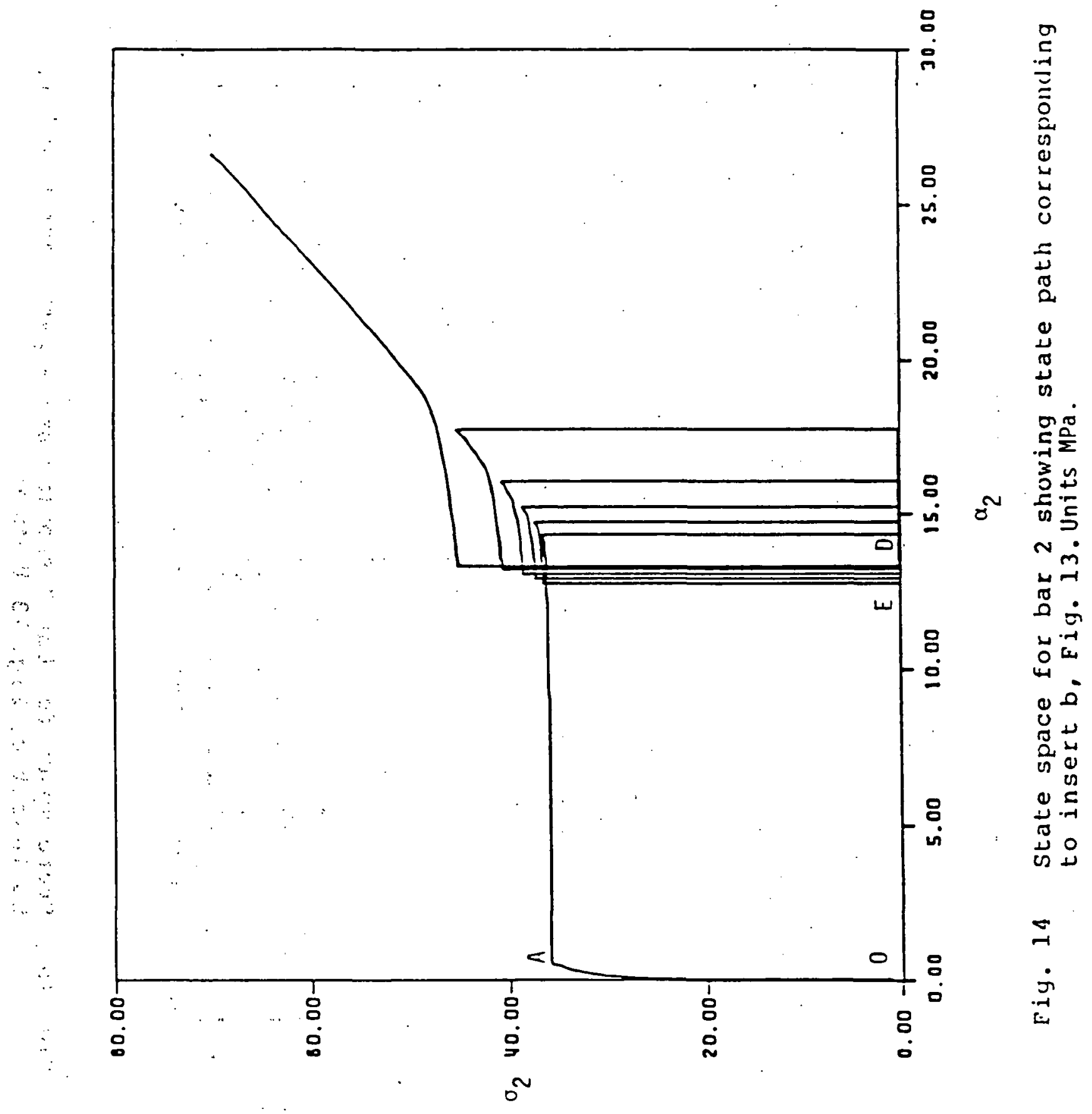




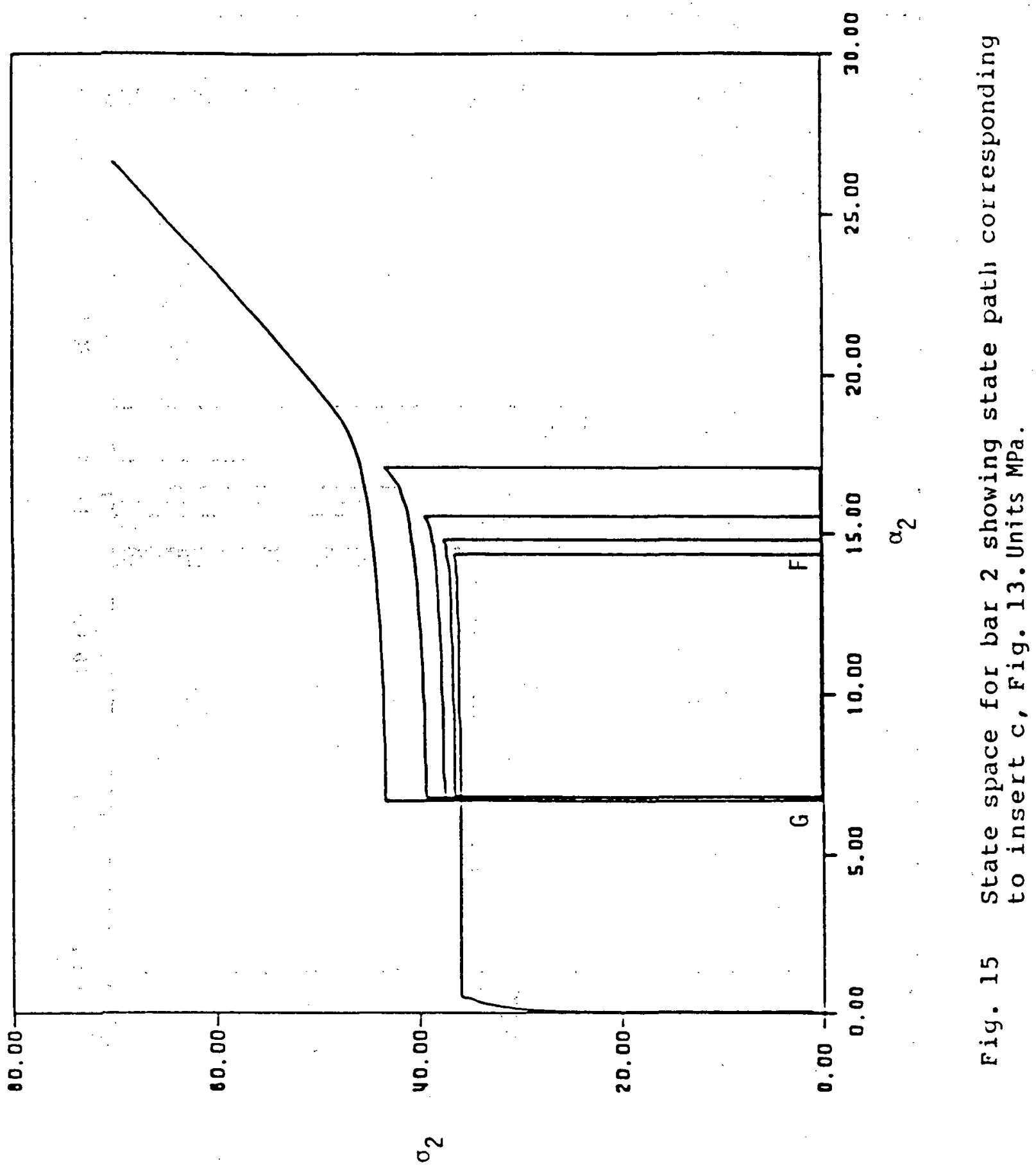




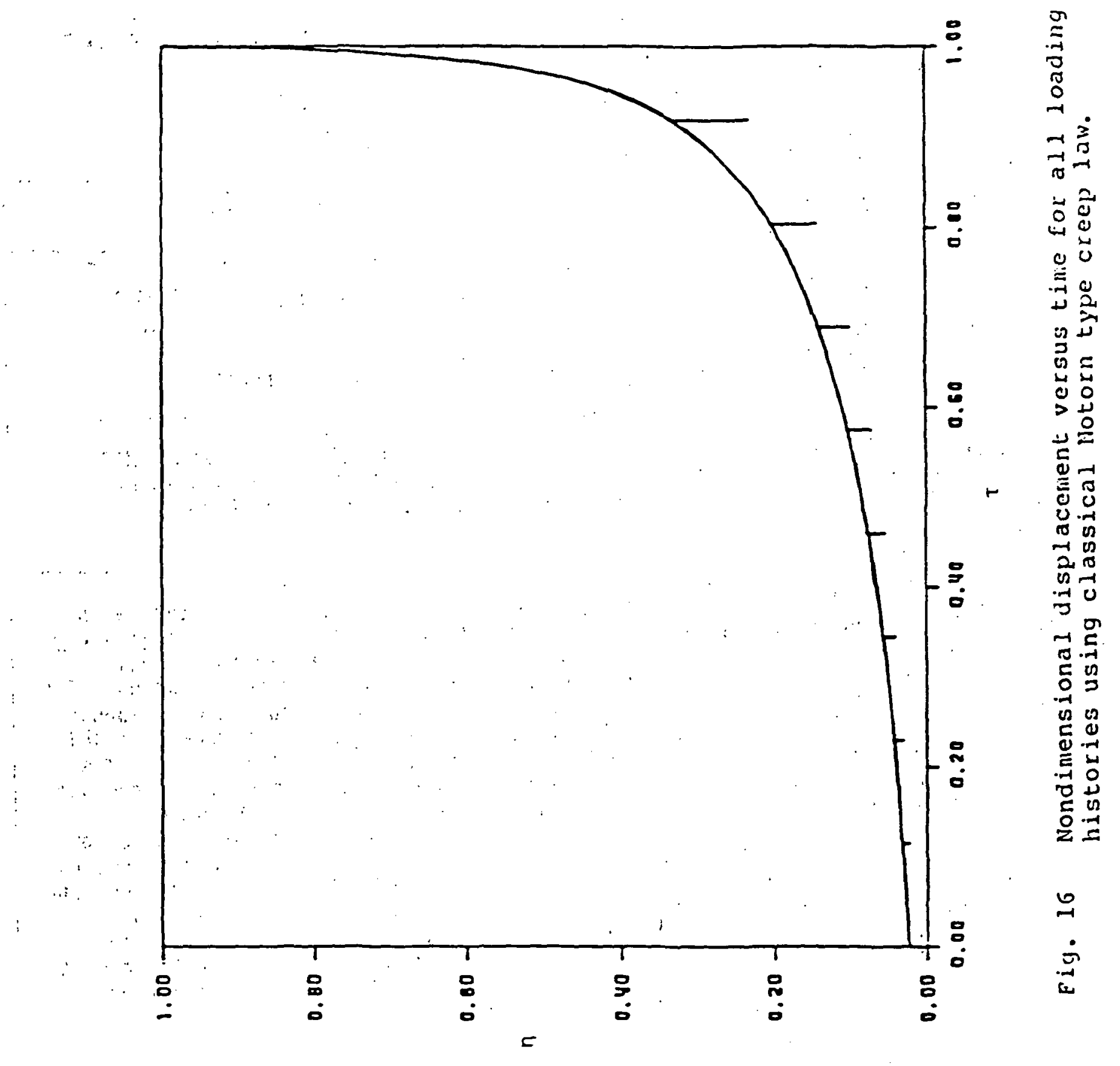




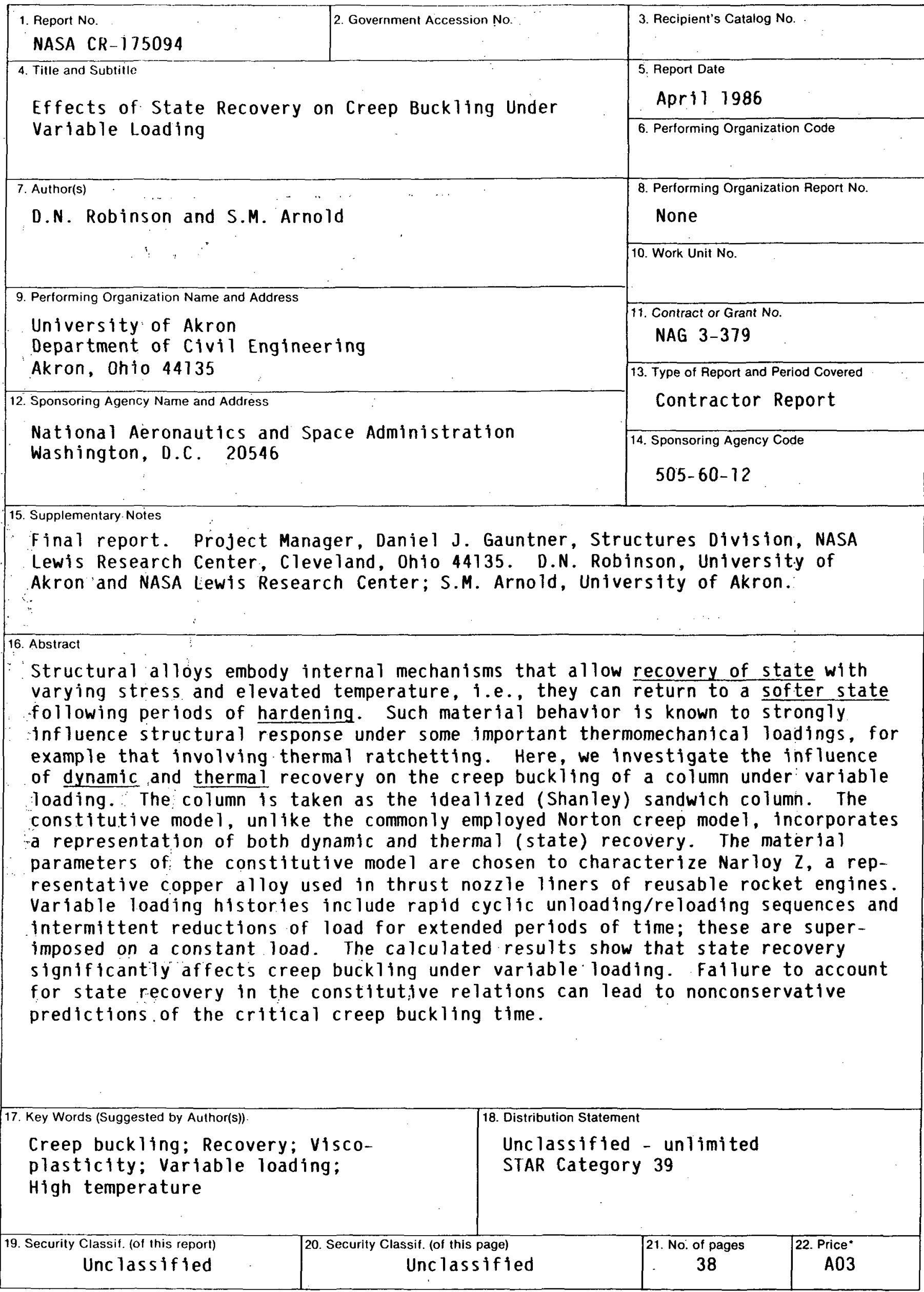

"For sale by the National Technical Information Service, Springfield, Virginia 22161 
National Aeronautics and

Space Administration

Lewis Research Center

Cleveland, Ohio 44135

Official Business

Penalty for Pivate Use \$300
SECOND CLASS MAIL

ADDRESS CORRECTION REQUESTED

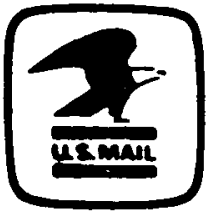

Postage and Fees Paid National Aeronautics and Space Administration NASA-451 